\title{
Overt Existential Closure in Bura (Central Chadic)
}

\author{
Malte Zimmermann \\ University of Potsdam
}

\section{Introduction}

The article presents a semantic-based account of the syntactic distribution of the morpheme adi in Bura. This morpheme is traditionally glossed as an existential predicate there is (Hoffmann 1955) and occurs only in a limited set of - at first sight - heterogeneous syntactic environments, namely (i.) in (most) negative clauses; (ii.) in thetic constructions used for introducing new discourse referents (there is $x$...); and (iii.) in existential clefts (there is some $x$ that ...). The article will identify the semantic contribution of adi and give a unified account of its distribution. It is argued that adi is an overt marker of existential closure that can bind individual or event variables with existential force. The insertion of adi is argued to be a last resort operation. It applies if and only if alternative means of existentially closing a variable fail. The analysis of adi as an overt indicator of existential closure has repercussions for semantic theory as whole. For once, given that adi is overt, it gives us a better insight into the workings and the grammatical locus of existential closure, which can be accessed only indirectly in European languages (Diesing 1992). Second, given that adi must existentially close off event variables in negative clauses, it can be used as a diagnostic for the ability of verbal predicates to introduce an event argument into the semantic representation (Kratzer 1995).

The structure of the article is as follows: Section 2 provides some background information on Bura. Section 3 lays out the main facts surrounding the distribution of adi. Section 4 presents the basic analysis. Section 5 extends the analysis to occurrences of adi in existential cleft-like structures. Section 6 discusses some general theoretical consequences and Section 7 concludes.

\section{Some Background on Bura}

Bura is a Central Chadic language of the Afro-Asiatic family. It is spoken by approximately 250.000 people in the Borno and Adamawa provinces of

This research was carried out as part of the project Focus in Chadic Languages within the special research group SFB 632 Information Structure, funded by the German Science Foundation (DFG), whose financial support is gratefully acknowledged. I would further like to thank my Bura consultant, Christopher Yusufu Mtaku, and Peggy Jakob for help in the data elicitation. 
Northeastern Nigeria and has the following general grammatical properties. It is a tone language with three level tones, High, Mid, and Low (not marked in what follows). Its basic word order is SVO as illustrated in (1):

$$
\begin{aligned}
& \text { kubili tsi mtika-ni } \\
& \text { K. slaughter chicken-DEF } \\
& \text { 'Kubili slaughtered the chicken.' }
\end{aligned}
$$

Bura has no overt case or tense morphology, but aspectual marking, cf. (2). In contrast to aspectual information, the temporal interpretation of a clause is subject to contextual licensing. Negation is expressed by a clause-final marker $w a$, which typically occurs in combination with adi, as shown in (3):
a. kubili $\varnothing$
tsi mtika
perfective
b. kubili akwa
tsi mtika
progressive
c. kubili ata
tsi mtika
future
d. kubili ana
tsi mtika
habitual

'K. slaughtered/ is slaughtering/ will slaughter/ slaughters a chicken.'

$\begin{array}{lccc}\text { kubili } & *(\text { adi }) \text { tsi } & \text { mtika-ni } & \text { wa } \\ \text { K. ADI slaughter } & \text { chicken-DEF } & \text { NEG } \\ \text { 'Kubili didn't slaughter the chicken.' }\end{array}$

Looking at the realization of nominal expressions, Bura has a postnominal definiteness marker $-n i$, cf. (1) and (3). Indefinite NPs typically occur as bare NPs, or they can be modified by laga 'some, a certain', cf. (4a,b). NPs with a general meaning, such as $m d a$ 'man, person', $s u$ 'thing', and $v i$ 'place', often have a non-specific (indeterminate) reading, meaning 'somebody', 'something', and 'somewhere', respectively, cf. (4b):
a. kubili
tsi
mtika (laga)
K. slaughter
chicken certain
'Kubili slaughtered a chicken / some chicken.'
b. tsa masta
su (laga)
$3 \mathrm{SG}$
buy
thing certain
'He bought something.'

\section{Data: The Distribution of adi}

As mentioned at the outset, the occurrence of the morpheme adi is restricted to three syntactic environments. First, adi must occur in negative eventive clauses, where it precedes both the verb and the aspectual marker: 


$$
\begin{array}{lllll}
\text { pindar adi ata sa mbal } & \text { wa } \\
\text { P. ADI FUT drink } & \text { beer } & \text { NEG } \\
\text { 'Pindar will not drink beer.' } & &
\end{array}
$$

Second, adi must occur in verbless thetic sentences with indefinite expressions that introduce new discourse referents, cf. (6ab):
a. akwa saka laga $[m d a$ adi ka mwanki ntufu $]$ at time some person ADI with wife five 'Once upon a time, there was a man with five wives.'
b. kakadu adi ata kira tebir book ADI on top table

'There is a book on the table.'

Third, adi occurs with indefinite NPs in cleft-like structures, such as (7).

$$
\begin{array}{lllll}
m d a & \text { adi } & {[\mathrm{ti}} & \text { tsa } & \text { kuga }] . \\
\text { person ADI } & \text { REL } & 3 \mathrm{sg} & \text { invite }
\end{array}
$$

'There is somebody that he invited. / SOMEBODY, he invited.'

Crucially, though, adi is illicit in affirmative sentences with a full verbal predicate, even when the sentence contains an indefinite expressions, cf. (8ab):
a. tsa (*adi) masta su
3SG ADI buy thing
'She bought something.'
b. mda (*adi) si
person ADI come
'Somebody/ A man came.'

The data in (5) to (8) allow for a first empirical generalization in (9):

(9) Distribution of adi (to be simplified below):

i. adi is (almost) always required under negation

ii. in affirmative clauses, adi is required with (non-specific) indefinite NPs in the absence of a lexical verb

This gives rise to the question of what is the unifying factor behind the disjunctive generalization in (9). We will turn to this question next. 


\section{Analysis: $A d i$ as an Indicator of Existential Closure}

\subsection{An Incorrect Hypothesis: Adi as an Existential Verb}

By just looking at (6) and (7) alone, one might get the erroneous impression that adi is a default copular verb with the meaning 'to be, to exist', which is inserted whenever there is no full verbal predicate (see the paraphrase in Hoffmann 1955). The structure of sentence (6b) would then be as shown in (6b'):

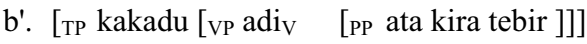

$$
\begin{aligned}
& \text { book exists on top table }
\end{aligned}
$$

However plausible this hypothesis might look at first sight, it is falsified by the following facts. First, adi cannot occur together with referential and quantified expressions in clefts, cf. (10ab). It follows that adi cannot be the default copular verb in a cleft sentence (more on clefts below). ${ }^{1}$
a. *kubili adi (an) [ti tsa kuga ] K. ADI PRT REL 3sg invite INTENDED: 'It is Kubili that he invited.'
b. *kəlara mda adi (an) [ti tsa kuga $]$ every man ADI PRT REL 3sg invite INTENDED: 'It is everybody/ just anybody that he invited.'

Second, there is no requirement for a Bura sentence to contain an overt verbal expression as witnessed by the fact that predicative constructions occur without a verb, cf. (11). It follows that adi is not inserted as a last resort dummy verb:

$$
\begin{aligned}
& \text { sal-ni [mdi-r hyipa ] } \\
& \text { man-DEF person-of teaching } \\
& \text { 'The man is a teacher.' }
\end{aligned}
$$

Third, the syntactic position of adi differs from that of verbs, with adi always preceding the preverbal aspectual marker, cf. (5). This is unlike what we find with any other verb. Furthermore, on this account, what would motivate the presence of adi in negated sentences, which do contain verbal predicates after all? Taken together, these facts provide strong evidence against an analysis of adi as an existential (copular) verb. An alternative analysis is required.

\footnotetext{
${ }^{1}$ As a matter of fact, there is evidence that the particle an takes over the function of an emphatic (non-verbal) copula in clefts, see Hartmann, Jakob \& Zimmermann (in prep.) and below.
} 


\subsection{Analyzing adi as an Existential Operator}

The alternative account of adi proposed here is based on adi's co-occurrence with indefinite expressions, which was illustrated in (6) and (7). It is well known that such indefinite NPs are analyzable as predicate-denoting expressions of type $<e, t>$, cf. (12ab). In analogous fashion, extended verbal projections such as vP (or AspP) can be construed as denoting event predicates, as in (12c).

$$
\begin{aligned}
& \text { a. } \llbracket \mathrm{mda} \rrbracket=\lambda \mathrm{x} \in \mathrm{D}_{\mathrm{e}} \cdot \text { person'( } \mathrm{x} \text { ) } \\
& \text { b. } \llbracket k a k a d u \rrbracket=\quad \lambda x \in D_{e} \text {. book' }(x) \\
& \text { c. «kubili } \varnothing \text { tsi mtika-ni \ } \\
& \text { K. PERF slaughter chicken-DEF } \\
& =\lambda \mathrm{e} \in \mathrm{D}_{\mathrm{v}} \text {. e is an event of Kubili killing the chicken completed by }
\end{aligned}
$$

Crucially, each of the predicate-denoting expressions in (12) introduces a variable that is not existentially bound. Adopting this analysis of indefinite NPs and vPs/ AspPs, the empirical generalization for the distribution of adi simplifies to (13):

\section{Distribution of adi (final generalization):}

Adi occurs whenever an individual or event variable must be existentially bound, but cannot be bound by alternative means.

As for the semantic role of adi, we can account for its functioning as an (existential) variable binder by making the following assumption: Adi denotes an existential operator that is introduced as a last resort whenever other means of variable binding fail to apply. We will see shortly what the alternative means of binding a variable in Bura are. The denotation of adi is given in (14):

$$
\llbracket \operatorname{adi}_{\exists} \rrbracket=\lambda \mathrm{P} \in \mathrm{D}_{<\sigma, \mathrm{t}>} . \exists \mathrm{x} \in \mathrm{D}_{\sigma}[\mathrm{P}(\mathrm{x})]
$$

This denotation is identical to the denotation of the existential predicate there is proposed e.g. in Milsark (1974), Blutner (1993) and McNally (1992, 1998).

As for its syntactic position in verbal clauses, adi occurs in a position preceding and c-commanding $\mathrm{vP}$ and $\mathrm{AspP}$, and thus any aspectual markers, if aspectual structure is present. Based on this, one can treat adi as adjoined to AspP in clauses containing a verb. We will not be concerned with the exact syntactic positon of adi in what follows, but see Fns. 2 and 5 .

\subsection{Applying the Analysis}

In what follows, we will show how the analysis of adi in 4.2 can account for the distribution of adi in Bura. We start by looking at affirmative verbal clauses, in 
which adi cannot occur. It is argued that it is the meaning of the lexical verb that brings about existential closure in such sentences, obviating the need for inserting adi. We will then proceed to the analysis of thetic (affirmative) sentences with indefinite NPs and no verbal predicate, which require adi, and to the occurrence of adi in negative (eventive) clauses.

Sentence (8a), repeated as (15), shows that adi is generally blocked from occurring in affirmative clauses with a verbal predicate:

$\begin{array}{lll}\text { tsa (*adi) } \quad \text { masta } & s u \\ \text { 3SG ADI } \quad \text { buy } & \text { thing } \\ \text { 'She bought something.' } & \end{array}$

The impossibility of adi in (15) suggests that the individual variable introduced by the indefinite NP $s u$ 'thing' is existentially closed by an alternative mechanism. More to the point, we will take up an idea first proposed in Carlson (1977) and assume that the individual variable introduced by an indefinite argument NP is existentially closed by the verb in the unmarked case of affirmative verbal sentences. Following van Geenhoven (1998) and McNally \& van Geenhoven (2005), Bura verbs are taken to be lexically ambiguous. They can denote relations between individuals on their basic interpretation, cf. (16a), but they can also denote relations between individuals and properties, $\mathrm{cf}$. (16bc):
a. $\llbracket \operatorname{masta}_{1} \rrbracket=\lambda y \in D_{\mathrm{e}} . \lambda \mathrm{x} \in \mathrm{D}_{\mathrm{e}} . \lambda \mathrm{e} . \mathrm{x}$ bought $\mathrm{y}$ in $\mathrm{e}$
b. $\llbracket \mathrm{masta}_{2} \rrbracket=\lambda \mathrm{P} \in \mathrm{D}_{<\mathrm{et}>} . \lambda \mathrm{x} \in \mathrm{D}_{\mathrm{e}} . \lambda \mathrm{e} . \exists \mathrm{y}[\mathrm{P}(\mathrm{y}) \wedge \mathrm{x}$ bought $\mathrm{y}$ in e $]$
c. $\llbracket \operatorname{masta}_{3} \rrbracket=\lambda \mathrm{P} \in \mathrm{D}_{<\mathrm{et}>} . \lambda \mathrm{Q} \in \mathrm{D}_{<\mathrm{et}>} . \lambda \mathrm{e} . \exists \mathrm{x}, \mathrm{y}[\mathrm{P}(\mathrm{y}) \& \mathrm{Q}(\mathrm{x}) \wedge \mathrm{x}$ bought $\mathrm{y}$ in $\mathrm{e}]$

The treatment of verbs proposed in (16) is an extension of Geenhoven's original analysis, which does not consider event arguments. As in van Geenhoven, the outermost argument cannot be bound by the verb itself, presumably in order to preserve the essential semantic nature of verbs as relating atomic entities, rather than sets of such entities. In van Geenhoven's case, the outermost argument is the subject argument. In (16a-c), it is the event argument. It is this inability of a verb to existentially bind its outermost event argument that will be of crucial importance for the analysis of adi in negated clauses.

Given the denotations in (16bc), Bura verbs like masta can combine with, and existentially bind one, or even two indefinite NP-arguments, as shown in (17) for the case of the indefinite object NP in (15). After combining with the verb meaning, the individual variable introduced by $s u$ is existentially bound:

$$
\begin{aligned}
& \llbracket \text { masta } \mathrm{su} \rrbracket=\llbracket \mathrm{masta}_{2} \rrbracket(\llbracket \mathrm{su} \rrbracket) \\
& \left.=\left[\lambda \mathrm{P} \in \mathrm{D}_{<\mathrm{e}, \mathrm{t}>} . \lambda \mathrm{x} \in \mathrm{D}_{\mathrm{e}} \cdot \lambda \mathrm{e} . \exists \mathrm{y}[\mathrm{P}(\mathrm{y}) \& \mathrm{x} \text { bought } \mathrm{y} \text { in } \mathrm{e}]\right]\left(\lambda \mathrm{x} \in \mathrm{D}_{\mathrm{e}} \text {. thing'( }{ }^{\prime}\right)\right) \\
& =\lambda \mathrm{x} \in \mathrm{D}_{\mathrm{e}} \cdot \lambda \mathrm{e} . \exists \mathrm{y} \text { [thing'(y) } \& \mathrm{x} \text { bought } \mathrm{y} \text { in e] }
\end{aligned}
$$


Evidence supporting the claim that the verb can bind indefinite object and subject NPs alike comes from the behaviour of indefinite subject NPs in the context of sentence-final negation. In (18), the bare indefinite subject takes narrow scope under the negation operator, which we take to c-command AspP:

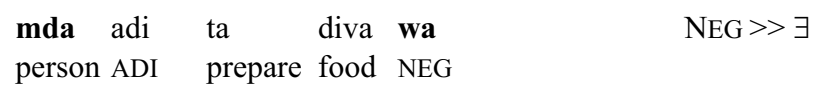

'Food is not prepared at all' = 'There is no event of a person making food NOT: 'Some person did not prepare food.'

On the analysis presented here, the existential operator binding the subject variable is part of the meaning of the verb. Since the verb is c-commanded by the negation operator, the scope facts fall out directly (Carlson 1977, McNally 1998).

With the analysis of the unmarked cases without adi in place, we can now proceed to the analysis of adi in thetic sentences with indefinite NPs, which do require the insertion of adi. Consider again (6b), repeated as (19).

kakadu adi ata kira tebir
book ADI on top table
'There is a book on the table,

There is no verbal predicate in (19), so the individual variable introduced by kakadu 'book' cannot be existentially closed in the usual way. Instead, the morpheme adi is inserted as a last resort and binds it. (20) shows the structure of the verbless predicative construction after merger of adi and the null T-head.

\section{$\left[\mathrm{TP}_{\varnothing} \mathrm{T}_{\varnothing}[\right.$ adi $[\mathrm{PredP}[\mathrm{NP}$ kakadu] [PP ata kira tebir]]]]}

Given that Spec,TP is always filled in Bura, the indefinite subject NP moves to SpecTP before Spell-Out, presumably in order to license $\mathrm{T}_{\varnothing}$. Semantically, though, the subject is interpreted in its base position. Neglecting syntactic movement, the simplified semantic derivation is given in (21). As required, the individual variable is existentially closed by $a d i .^{2}$

\footnotetext{
${ }^{2}$ An alternative analysis of (19) suggest itself, on which adi is right-adjoined to a complex NP consisting of the head noun kakadu 'book' and a PP-modifier, cf. (i):

$$
\text { [NP kakadu [PP ata kira tebir]] adi }
$$

In the course of the syntactic derivation, the PP-complement would extrapose to the right of adi, yielding the observable surface order. This analysis crucially relies on the possibility of PP-rightadjunction in Bura, for which we lack independent evidence. Furthermore, on standard accounts, it is not quite clear how are bare NP-constituent could act as a proposition-denoting, clause-like element on its own. In any event, the assumption of the structure in (i) plus extraposition would
} 


$$
\begin{aligned}
& \llbracket 20 \rrbracket=\llbracket \operatorname{adi} \rrbracket(\llbracket \text { PredP } \rrbracket) \\
& =\left[\lambda P \in D_{<e, t>} . \exists x[P(x)]\right]\left(\lambda x \in D_{e} \cdot b_{b o o k}(x) \wedge \text { on' }(x, \text { ty. table' }(y))\right) \\
& =\exists x\left[\text { book' }^{\prime}(x) \wedge \text { on' }^{\prime}(x, \text { ty. table' }(y))\right]
\end{aligned}
$$

Let us finally turn to the negative eventive clauses such as (3), repeated as (22), which do require adi, nothwithstanding the fact that they contain a lexical verb.

kubili adi $\quad$ tsi $\quad$ mtika-ni $]$ wa
K. ADI slaughter chicken-DEF NEG
'Kubili did not slaughter the chicken.'

Recall from above that, by assumption, the verb itself is unable to existentially close its outermost event-argument. In this situation, adi adjoins to AspP below negation and existentially closes the event variable introduced (but not bound) by the main verb $t s i$. The syntactic structure of (22) and its semantic derivation are spelt-out in (23a) and (23bc), respectively. (23b) shows the semantic result of combining adi with AspP. This formula, or rather the tensed and intensionalized version thereof, then serves as the complement of negation, yielding (23c):

a. [тP $\operatorname{kubili}_{1}\left[\mathrm{NegP}\right.$ [ adi [AspP $\varnothing\left[{ }_{\text {vр }} \mathrm{t}_{1}\right.$ tsi mitka-ni]]] wa] $]$

b. $\llbracket$ adi $\rrbracket(\llbracket A s p P \rrbracket)$

$=\left[\lambda \mathrm{P} \in \mathrm{D}_{<\mathrm{v}, \mathrm{t}\rangle} . \exists \mathrm{e}[\mathrm{P}(\mathrm{e})]\right]\left(\lambda \mathrm{e} \in \mathrm{D}_{\mathrm{v}}\right.$. e is an event of Kubili killing a chicken \& time $\left.(e)<t_{R}\right) \quad\left(t_{R}=\right.$ reference time, cf. Kratzer 1998)

$=\exists \mathrm{e}\left[\mathrm{e}\right.$ is an event of Kubili killing a chicken \& time $\left.(\mathrm{e})<\mathrm{t}_{\mathrm{R}}\right]$

c. $\llbracket(22) \rrbracket=\neg \exists \mathrm{e}\left[\mathrm{e}\right.$ is an event of Kubili killing a chicken $\&$ time $\left.(\mathrm{e})<\mathrm{t}_{\mathrm{R}}\right]$

Assuming that this analysis is correct, the question arises as to what would force the obligatory occurrence of adi in negative eventive clauses? It seems, indeed, as if sentential negation in Bura would require existential closure over events such that it can apply: NEG $>\exists \mathrm{e}$. A reason for this could be that the sentential negation marker wa can only operate on closed propositions, but not on event predicates. Whatever the exact reason, it is interesting to note that similar facts concerning the obligatory closure of events below negation have been observed for Romance by Herburger (2002) and for Germanic languages by Zeijlstra (2004). See also Section 6 for additional evidence from English. The fact that Bura behaves like European languages in this respect may very well point to a potential universal concerning the interaction of negation and event structure in natural language.

A strong piece of evidence in support of the claim that the presence of adi in negative clauses is forced by the need to close off the event variable under negation comes from negative sentences with individual-level predicates, such as

go at the expense of a unified syntactic analysis of adi, which would occur left-adjoined to AspP in verbal clauses, and right-adjoined to NP in non-verbal clauses. 
to be intelligent, to have the ability to, etc. According to Kratzer (1995), these predicates differ from so-called stage-level predicates in that they do not introduce an event argument into the semantic representation. Among other things, this can be seen from the fact that they cannot be quantified over by an adverbial quantifier in the absence of indefinite NPs, due to a ban on vacuous quantification. There is no event variable that the adverbial quantifier could bind. The difference between the stage-level predicate to speak Hausa with an event argument and the individual-level predicate to know Hausa without one is illustrated in (24ab). The ungrammaticality of (24b) follows if the predicate to know Hausa does not introduce an event variable to be quantified over by always.
a. Always e [if Musa speaks Hausa (e)], [he speaks it well (e)].

b. *Always e [if Musa knows Hausa], [he knows it well]

Now, if the presence of adi in negative eventive clauses is triggered by the need of the verb's event variable to be bound, adi is predicted to be absent with individual-level predicates, which do not introduce an event variable to begin with. Interestingly, this is indeed what we find with the individual-level predicate asinda mya Bura 'to know Bura', as shown in (25):

$$
\begin{aligned}
& \text { Musa asinda mya } \quad \text { Bura wa } \\
& \text { Musa know language Bura NEG } \\
& \text { 'Musa does not understand / cannot speak Bura.' }
\end{aligned}
$$

It remains to be seen whether the same state of affairs obtains with other individual-level predicates. Note in passing, though, that if these predicates behave like asinda mya Bura in (25), this will give us a very powerful diagnostic for the event structure of predicates in Bura (and possibly beyond).

Summing up so far, the proposed analysis has can account for the occurrence of adi in two syntactic environments. In verbless thetic sentences, adi binds the individual variable introduced by an indefinite NP. In negative eventive sentences, adi binds the event variable introduced by the verb. What is still missing is an account of the occurrence of adi in existential cleft-like structures.

\section{Adi in Clefts and Cleft-like Structures}

This section presents an account for the occurrence of adi with indefinite NPs in existential cleft-like structures, such as (7), repeated as (26).

$$
\begin{array}{lllll}
m d a & \text { adi } & \text { [ti } & \text { tsa } & \text { kuga }] . \\
\text { person } & \text { ADI } & \text { REL } & 3 \mathrm{sg} & \text { invite }
\end{array}
$$

'There is somebody that he invited. / SOMEBODY, he invited.' 
To this end, we will compare existential clefts with adi (there is someone that...) with ordinary identificational focus clefts (it is $x$ that ...) in 5.1. In Section 5.2, we argue that what looks like an existential cleft containing adi is really a sequence of two clauses, which are semantically linked by means of dynamic binding. Section 5.3 looks at the occurrence of adi in negative clefts, which is argued to constitute a subcase of adi under sentential negation.

\subsection{Focus Clefts and Existential adi-Clefts: A Comparison}

The first observation relevant for the analysis of existential cleft-like structures with adi is that these are not restricted to occur with non-specific indeterminate indefinites, such as $m d a$ 'man, person' in (26). They are equally fine with more specific indefinites, such as nkwa Bura 'a certain/some Bura girl' in (27):

$$
\begin{array}{lllllll}
\text { nkwa } & \text { Bura } & \text { adi } & \text { ti } & \text { kəlara mda bara } & \text { kəla] } \\
\text { girl } & \text { Bura } & \text { ADI } & \text { REL } & \text { every person want } & \text { marry }
\end{array}
$$

'There was some/ a certain Bura girl that each person wanted to marry.'

The second relevant observation is that existential cleft-like structures with adi differ in form and meaning from ordinary clefts used in focus marking (Hartmann, Jakob \& Zimmermann, in prep.).
a. mtika adi [ti Ladi sima $]$
(existential cleft)
chicken ADI REL Ladi eat
'There is a chicken that Ladi ate.'

b. Q: What did Ladi eat?

A: mtika an $[\mathrm{ti}$ Ladi sima $]$ (focus cleft)
chicken PRT REL Ladi eat
'It is chicken that Ladi ate.'

Ordinary focus clefts such as (28b) never contain adi, but invariably the marker an, which is analyzed as an emphatic particle in Hoffmann (1955), and as a presuppositional copula in $\mathrm{T}$ in Hartmann, Jakob \& Zimmermann (in prep.). The structure of (28b) is shown in (29):

$$
\text { [TP } \left.\text { mtika }_{i}\left[\mathrm{~T} \text {, an }\left[\mathrm{CP}_{\mathrm{OP}} \mathrm{Op}_{\mathrm{i}, 1} \text { ti Ladi sima } \mathrm{t}_{1}\right]\right]\right]
$$

The presence of an in (28b) has a twofold semantic effect, cf. (30). It invokes a set of focus alternatives and adds a weak uniqueness presupposition to the effect that the denotation of the clefted constituent is the only element from a set of alternatives that satisfies the denotation of the relative clause, which is a 
property. ${ }^{3}$ Apart from this special focus semantics, the meaning in (30) is the one assumed for copular be by Williams (1983) and Partee (1987).

$$
\llbracket \operatorname{an} \rrbracket=\lambda \mathrm{P} \in \mathrm{D}_{<\mathrm{e}, \mathrm{t}} . \lambda \mathrm{x} \in \mathrm{D}_{\mathrm{e}} . \mathrm{P}(\mathrm{x}), \text { defined iff } \forall \mathrm{y} \in \mathrm{ALT}(\mathrm{x}): \mathrm{P}(\mathrm{y}) \rightarrow \mathrm{y}=\mathrm{x}
$$

Notice that the clefted indefinite mtika in (28b) does not require the presence of adi. Consequently, the individual variable introduced by mtika must be closed in a different way for the sentence to be well-formed. We assume that, just as with verbal predicates, it is the copular element an, which does the job of existentially closing the variable. ${ }^{4}$ As a result, no insertion of adi is required.

In contrast, existential cleft-like structures such as (28a) always contain adi, but never the copula an. In fact, the addition of an triggers a change in structure and meaning. In (28c), the co-occurrence of adi and an leads to the construal of a bi-clausal structure expressing a consecutive or causative sequence of two propositions.

$$
\begin{aligned}
& \text { c. [CP mtika adi] an [CP ti Ladi sima] } \\
& \text { chicken ADI PRT REL Ladi eat } \\
& \text { 'There was chicken, so Ladi ate.' } \\
& \text { (lit. 'It is there being a chicken that Ladi ate.') }
\end{aligned}
$$

The two clauses in (28c) are structurally and semantically linked by the copular element an, with adi existentially closing off the individual variable in the first clause. ${ }^{5}$ In what follows, we will argue that a similar bi-clausal structure lies at the heart of existential cleft-like structures with adi.

\footnotetext{
${ }^{3}$ The complementary distribution of adi and an in (28ab) might at first suggest that adi, too, is an existential copula. On closer inspection, though, the syntax and semantics of the two elements are quite different. Semantically, adi does not take two arguments, but only one. Syntactically, adi can occur in more positions than the copula an, and the two elements can even co-occur in negated clefts. See Section 5.3 for more discussion.

${ }^{4} \mathrm{~A}$ possible lexical entry for this type-shifted variant of an is given in (i):

$$
\begin{aligned}
{\left[\left[\mathrm{an}_{2}\right]\right]=\lambda \mathrm{P} \in \mathrm{D}_{<\mathrm{e}, \mathrm{t}>} . \lambda \mathrm{Q} \in \mathrm{D}_{<\mathrm{e}, \mathrm{t}} . \lambda \mathrm{e} . \exists \mathbf{x}[\mathrm{Q}(\mathrm{x}) \& \mathrm{P}(\mathrm{x}) \text { in e }], } \\
\\
\text { defined iff } \forall \mathrm{R} \in \mathrm{ALT}(\mathrm{Q}):(\exists \mathrm{x}, \mathrm{e}[\mathrm{R}(\mathrm{x}) \& \mathrm{P}(\mathrm{x}) \text { in e] }) \rightarrow \mathrm{R}=\mathrm{Q}
\end{aligned}
$$

The analysis of an proposed here treats copular elements as semantically parallel to verbal predicates. They relate individuals with properties and they can even introduce event arguments. Section 5.3 puts forward more evidence in favor of the eventive nature of clefts. The crucial difference of copular elements and verbs is that the former can never relate just atomic entities with one another, as they crucially select for at least one property-denoting argument.

${ }^{5}$ Again, as speculated in Fn.2, adi could be taken to directly adjoin to the clefted NP in (28c). In the absence of further syntactic evidence and given that the general semantic analysis of adi is unaffected by it, we will not take a stand on this issue. What is important for our present concerns is that the clefted part of (28c) denotes a proposition of its own.
} 


\subsection{Existential Cleft-Structures with adi: Two Clauses + Dynamic Binding}

Extending the analysis of (28c) to existential cleft-like structures, such as (28a), we will assume that these, too, consist of two separate clauses, which are loosely coordinated. The syntactic structure for (28a) is shown in (31).

$$
\begin{array}{rlll}
{\left[\begin{array}{cl}
\text { CP }\left[\begin{array}{cc}
\text { CPtika } & \text { adi }
\end{array}\right] \\
\text { chicken ADI }
\end{array} \quad\left[\begin{array}{llll}
\text { CP } & \text { ti } & \text { Ladi } & \text { sima }
\end{array}\right]\right.} \\
\text { REL } & \text { Ladi } & \text { eat }
\end{array}
$$

How to interpret the structure in (31)? Informally speaking, what seems to be going on is that the first clause asserts the existence of an individual, which then serves as the topic for the second clause, which acts as a comment on it. More formally speaking, the two clauses are linked by a process of cross-sentential binding. The semantic derivation of (31) proceeds a follows. First, the presence of adi in the first clause leads to existential closure of the individual variable $x$ introduced by the indefinite mtika:

$$
\text { a. 【mtika adi } \rrbracket \quad=\exists x\left[\operatorname{chicken}^{\prime}(\mathrm{x})\right]
$$

In a second step, the open proposition expressed by the relative clause $t i$ Ladi sima, cf. (32b) is predicated of the same variable $x$ by a process of dynamic binding, in which the existential quantifier of the first clause binds the variable $x$ in the second across the sentential boundary, cf. (32c).

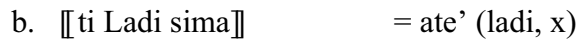

$$
\begin{aligned}
& \text { c. 【mtika adi ti Ladi sima } \left.=\exists_{\mathrm{DYN}} \mathrm{X} \text { [chicken'(x)] } \wedge_{\mathrm{DYN}} \text { ate' (ladi, } \mathrm{x}\right)
\end{aligned}
$$

Technically, the effects of dynamic binding across sentence boundaries can be implemented in various ways, e.g. by using Kamp \& Reyle's (1993) DRT, or Groenendijk \& Stokhof's (1991) Dynamic Predicate Logic. The semantic effect is the same under both implementations: (31) will be interpreted in parallel to the English sentence pair (33a), which can be paraphrased as (33b):
a. There was a chicken ${ }_{\mathrm{i}}$. Ladi ate $\mathrm{it}_{\mathrm{i}}$.
b. $\approx$ There was a chicken that Ladi ate.

In sum, existential cleft-like structures in Bura consist of two separate clauses, each containing a variable that is existentially closed by an instance of adi in the first clause. The binding of adi into the second clause is brought about by a process of dynamic binding. 6

\footnotetext{
${ }^{6}$ Again, an alternative analysis of (28a) is feasible, which gets by without dynamic binding and which would be based on the underlying structure in (i):
} 


\subsection{Occurrence of adi in Negative Clefts}

Not surprisingly, adi also occurs in negative clefts, when negation takes scope over the entire cleft and not just the relative clause, cf. (34ab). (34ab) also show that adi occurs with individual-denoting and property-denoting expressions alike.
a. adi Kubili an simamya mtika ni wa ADI K. PRT eat chicken-DEF NEG
'It is not Kubili who ate the chicken.'
b. adi mtika an ti Kubili sim wa
ADI chicken PRT REL Kubili eat NEG
'It is not chicken that Kubili ate.'

The fact that the well-formedness of adi in (34a) is not contingent on the simultaneous presence of an indefinite NP suggests that it does not existentially close an individual variable in these cases. Rather, the obligatory occurrence of adi in negated clefts can be assumed to be triggered by the need to existentially close an event variable introduced by the copular element an, see Fn. 4. The semantic derivation for (34a) is indicated in (35):

$$
\begin{aligned}
\llbracket(34 \mathrm{a}) \rrbracket & =\llbracket \operatorname{adi} \rrbracket(\llbracket \text { Kubili an simamya mtika ni wa } \rrbracket \\
& =\left[\lambda \mathrm{P} \in \mathrm{D}_{<\mathrm{v}, \triangleright>} . \exists \mathrm{e}[\mathrm{P}(\mathrm{e})]\right](\lambda \mathrm{e} .[\text { it is Kubili that ate the chicken in } \mathrm{e}]) \\
& =\exists \mathrm{e}[\text { it is Kubili that ate the chicken in e] }
\end{aligned}
$$

The assumption that cleft constructions involve an event structure of their own is supported by the fact that they can be quantified over by adverbial quantifiers such as always in (36ab), at least in English:
a. It is always Kubili that eats the chicken.

b. It was always chicken that Kubili ate.

On this analysis, then, the occurrence of adi in negative clefts is just a special sub-case of the occurrence of adi under sentential negation.

(i) $\quad[\mathrm{NP}$ mtika [ti Ladi sima $]]$ adi

In the course of the syntactic derivation, the relative clause would be extraposed to the right in order to yield the observable surface structure. The attraction of this alternative account lies in the fact that it allows for a unified analysis of adi in thetic utterances and in existential cleft-like structures that can do without dynamic binding. In addition, this analysis would directly account for the presence of the relative linker in (28a). However, it also faces the problems mentioned above in Fn.2. In particular, the analysis rests heavily on the possibility of extraposition to the right in Bura, for which we lack independent evidence at present. 


\section{Consequences and Problems}

This section points out a number of theoretical consequences of the account of adi as introducing existential closure over event and individual variables. In addition, it discusses a number of further issues raised by the proposed analysis.

\subsection{Locus and Source of Existential Import: Cross-Linguistic Issues}

Various sources of existential import have been proposed for a range of languages in the literature. The following is a selection of devices found in the literature.

i. The verb meaning itself, which induces existential closure over individual variables (van Geenoven 1998, McNally \& van Geenhoven 2005).

ii. An anti-passive morpheme that adjoins to $\mathrm{V}$ and existentially closes off individual variables (Deal 2006).

iii. Aspectual heads, which existentially bind event variables (Kratzer 1998).

iv. An abstract operator inserted at the VP-boundary at logical-conceptual form, which binds individual and event variables (Diesing 1992).

To these, we now add the existential morpheme adi, which is located at the $\mathrm{vP} /$ AspP-boundary, and which triggers existential closure over event and individual variables alike. When viewed from a cross-linguistic perspective, adi looks very much like Diesing's operator in its ability to range over individuals and events. It is further interesting to note that all grammatical devices proposed, including adi, are located within or at the edge of the (extended) verbal projection, hinting at a potential universal. Finally, it should be pointed out again that the default source of existential closure in Bura is the meaning of the lexical verb.

\subsection{The Argument Structure of Verbs}

The proposed analysis of existential closure in Bura has repercussions for the analysis of the argument structure of verbs as well. Taking - as we do here - the absence of adi to indicate that the existential import comes from the verb, it follows that Bura verbs can existentially close subject and object variables alike. This was shown in (8ab), repeated as (37):
a. tsa
masta
su
b. $m d a$ si
$3 \mathrm{SG}$
buy
thing
person come
'She bought something.'
'Somebody/ A man came.'

Additional evidence for the claim that subject variables in Bura can be bound by an existential quantifier in the meaning of the verb came from the fact that indefinite subject NPs take semantic scope under negation, cf. (18). The observed parallel behavior of indefinite subject and object NPs in Bura with respect to existential closure is of theoretical relevance, for it suggests that the two 
arguments should be treated on a par structurally, i.e. both should be proper arguments of the verb. If, in contrast, existential import came from the verb meaning itself, but if the agent (= subject) argument was not introduced as part of the verb meaning, as argued e.g. In Kratzer (2002), the observed symmetry of subjects and objects would be unexpected.

Finally, as already pointed out at the end of Section 4.3 , the presence or absence of adi in negative sentences may serve as a powerful diagnostic tool into the event structure of verbs. The distribution of adi thus proves a valuable diagnostic for the argument structure of verbs in general.

\subsection{Event Structure and Sentential Negation}

In Section 4.3, we argued that the obligatory occurrence of adi in negated clauses follows from the necessity for an eventive predicate to be existentially closed before sentential negation applies. Somehow, sentential negation seems to be unable to apply to propositions with an open event argument.

$$
* \llbracket N E G \rrbracket(\lambda e . \varphi(e))
$$

As already mentioned, it is far from clear what should be the deeper reasons behind this restriction. After all, predicate negation with the prefixes in- and unis possible in the individual domain, at least as long as the complement domain is (contextually) restricted in some way. Relevant examples in question are morphologically negated predicates, such as irresponsible, un-British and undead. So, perhaps, the restriction in (38) has to do with the specific ontological nature of events and event predicates? Perhaps it is just too uninformative to negate an event predicate, given that events are typically not sortally restricted and the complement set of event predicates in principle unbounded? We will have to leave this matter open for further research. What we can show, though, is that the observed restriction on existential closure over events below sentential negation holds for English, too. A priori, the sentence in (39) could be assigned the two readings in (39i) and (39ii), respectively:

(39) Yesterday, Peter did not see a cat.

i. $\neg \exists \mathbf{e}\left[\right.$ time $(\mathrm{e}) \subseteq$ yesterday' $\wedge \exists \mathrm{x}\left[\right.$ cat' $^{\prime}(\mathrm{x}) \wedge$ see' $^{\prime}(\mathrm{e}$, peter, $\left.\left.\mathrm{x})\right]\right]$ $\approx$ there is no event of Peter's seeing a cat that took place yesterday

ii. $\exists \mathbf{e}\left[\right.$ time $(\mathrm{e}) \subseteq$ yesterday' $\wedge \exists \mathrm{x}\left[\right.$ cat' $^{\prime}(\mathrm{x}) \wedge \neg$ see' $^{\prime}(\mathrm{e}$, peter, $\left.\left.\mathrm{x})\right]\right]$ $\approx$ there is an event of Peter not seeing a cat that took place yesterday

On reading (39ii), the relevant interpretation with negation applying below existential closure over events, (39) should be true even if Peter DID see one or more cats, unless he saw cats all the time. But this is not what (39) means. Nor does it mean (39iii), with the event argument contextually bound under negation. 
iii. $\left[\operatorname{time}\left(\mathrm{g}\left(\mathrm{e}_{1}\right)\right) \subseteq\right.$ yesterday' $\wedge \exists \mathrm{x}\left[\right.$ cat' $^{\prime}(\mathrm{x}) \wedge \neg$ see' $^{\prime}\left(\mathrm{g}\left(\mathrm{e}_{1}\right)\right.$, peter, $\left.\left.\left.\mathrm{x}\right)\right]\right]$ $\approx$ a contextually given event $e_{I}$ took place yesterday which was an event of Peter not seeing a cat.

In sum, the only possible semantic representation of (39) is (39i), where existential closure over the event variable applies before sentential negation, $\mathrm{cf}$. also Kratzer (1998).

\subsection{On the Absence of adi in Affirmative Clauses with Verbs}

The account presented so far poses one final puzzle. So far, we have not said anything about the fact that adi cannot existentially close off the event variable in affirmative verbal clauses, such as (8a), repeated as (40):

*tsa adi masta $s u$
3SG ADI buy thing
INTENDED: 'She bought something.'

The absence of adi in affirmative episodic clauses implies that the event variable is never existentially closed in such clauses, contrary to standard assumptions in the literature, cf. Parsons (1990). Instead, it seems as if simple affirmative clauses in Bura typically referred to particular events that are contextually bound. Formally, this is illustrated in (41):

$$
\llbracket \text { tsa masta su } \rrbracket^{g}=\left[\text { time }\left(g\left(e_{1}\right)\right)<g\left(t_{R}\right) \wedge \exists x\left[\text { thing' }(x) \wedge \text { buy' }\left(g\left(e_{1}\right), \text { peter, } x\right)\right]\right]
$$

From a discourse-semantic perspective, this assumption does not seem too strange. It is well-known that questions that are typically used for eliciting allnew utterances with sentence focus, such as What happened? or What is going on?, presuppose the existence of a particular event that the elicited answer must make reference to. More generally, affirmative episodic sentences in larger discourse units are not uttered out of the blue. Typically, a sentence in which the verb meaning seemingly introduces a new event is understood as a response to an explicit or implicit question, such as What happened next? or Which e caused e'?

The possibility of contextual binding notwithstanding, we expect there to be cases where the existence of an event does form part of the truth-conditions of a clause, and where existential closure should therefore form part of the semantic representation. A possible case in question is the conditional clause in (42a), with the paraphrase in $(42 b)$ :

(42) a. Whenever Peter comes to a party, Mary leaves immediately.

b. Whenever there is an event of Peter coming to a party, there will be a sub-sequent event of Mary's leaving the party. 
If the verb is unable to bind its outermost event argument by itself (cf. Section 4.3 ), and if conditionals such as (42a) involve an existential statement over events, we would expect adi to occur in the Bura counterpart of (42a). At present, no data on Bura conditionals are available, but there ARE cases where adi is inserted in order to introduce an existential statement over events. A case in point are yes/no-questions, which allow for the optional insertion of adi:

$$
\begin{aligned}
& \text { Thla (adi) akwa di nda ya? } \\
& \text { cattle ADI in place DEM Q } \\
& \text { - ADI: 'Is there cattle in that village?' } \\
& \text { +ADI: 'IS there cattle in that village?' }
\end{aligned}
$$

(lit. 'Does a situation of there being cattle in that village obtain?')

As a first approximation, the semantic effect of inserting adi in (43) seems to consist in questioning the existence of a particular event or situation, and not so much in questioning the truth of the proposition expressed by the clause without adi. If this is correct, we would expect further (optional) instances of adi in Bura affirmative clauses, whenever the existence of an event is explicitly at stake.

\section{Conclusion}

The Central Chadic language Bura exhibits an existential morpheme adi, which is introduced by means of a last resort operation and binds an otherwise free individual or event variable. The default source for existential closure lies in the meaning of the verb. This alternative mechanism fails in the absence of lexical verbs, or if the outermost event variable introduced by the verb meaning must be bound, e.g. under sentential negation. The analysis proposed accounts for the occurrence of adi in thetic verbless clauses, in existential clefts, and under negation (with stage-level individuals), as well as for its absence in affirmative clauses with lexical verbs. Finally, it was shown that the discussion of a particular semantic phenomenon in a non-European language like Bura is not only interesting in its own right, but has repercussions for semantic theory in general.

\section{References}

Blutner, Reinhard: 1993, 'Dynamic Generalized Quantifiers and Existential Sentences in Natural Languages', Journal of Semantics 10, 33-64.

Carlson, Gregory N.: 1977, Reference to Kinds in English, Doctoral Disseration, UMass, Amherst.

Deal, Amy-Rose: 2007, 'Semantic Evidence for Antipassivization in Nez Perce', Presentation at SULA 4, Sao Paulo. 
Diesing, Molly: 1992, Indefinites, MIT Press, Cambridge, MA.

Groenendijk, Jeroen \& Martin Stokhof: 1991. 'Dynamic Predicate Logic', Linguistics and Philosophy 14, 39-100.

Hartmann, Katharina, Peggy Jakob, and Malte Zimmermann: in prep., 'Focus

Marking in Bura', Ms., Humboldt University Berlin \& Potsdam University.

Herburger, Elena: 2002, 'The Negative Concord Puzzle Revisited', Natural Language Semantics 9, 289-333.

Hoffmann, Carl L.: 1955, Untersuchungen zur Struktur und sprachlichen Stellung des Bura, Doctoral Dissertation, Hamburg University.

Kamp, Hans and Uwe Reyle: 1993, From Discourse to Logic, Kluwer, Dordrecht.

Kratzer, Angelika: 1995, 'Stage-Level and Individual-Level Predicates', in G. Carlson and F. Pelletier (eds.) The Generic Book, University of Chicago Press, Chicago, 125-175.

Kratzer, Angelika: 1998, 'More Structural Analogies Between Pronouns and Tenses', in D. Strolovich and A. Lawson (eds) Proceedings of SALT 8. CLC Publications, Cornell University, Ithaca, 92-110.

Kratzer, Angelika: 2002, 'The Event Argument and the Semantics of Verbs', Ms., UMass, Amherst, http://semanticsarchive.net/Archive/GU1NWM4Z/

McNally, Louise: 1992, An Interpretation for the English Existential Construction, Doctoral Dissertation, UCSC.

McNally, Louise: 1998, 'Existential Sentences Without Existential Quantification', Linguistics and Philosophy 21, 353-392.

Milsark, Gareth: 1974, Existential Sentences in English, Doctoral Dissertation, MIT.

Parsons. Terence: 1990, Events in the Semantics of English: A Study in Subatomic Semantics, MIT Press, Cambridge, MA:

Partee, Barbara H.: 1987, 'Noun Phrase Interpretation and Type-Shifting Principles', in J. Groenendijk, M. Stokhof \& D. de Jongh (eds) Studies in Discourse Representation Theory and the Theory of Generalized Quantifiers, Foris, Dordrecht, 115-143.

van Geenhoven, Veerle: 1998, Semantic Incorporation and Indefinite Descriptions: Semantic and Syntactic Aspects of Noun Incorporation in West Greenlandic, CSLI Publications, Stanford.

van Geenhoven, Veerle and Louise McNally: 2005, 'On the property analysis of opaque complements', Lingua 115, 885-914.

Williams, Edwin: 1983. Semantic vs. syntactic categories. Linguistics and Philosophy 6, 423-446.

Zeijlstra, Hedde: 2004, Sentential Negation and Negative Concord. Doctoral Dissertation, University of Amsterdam. LOT Publications, Utrecht. 